
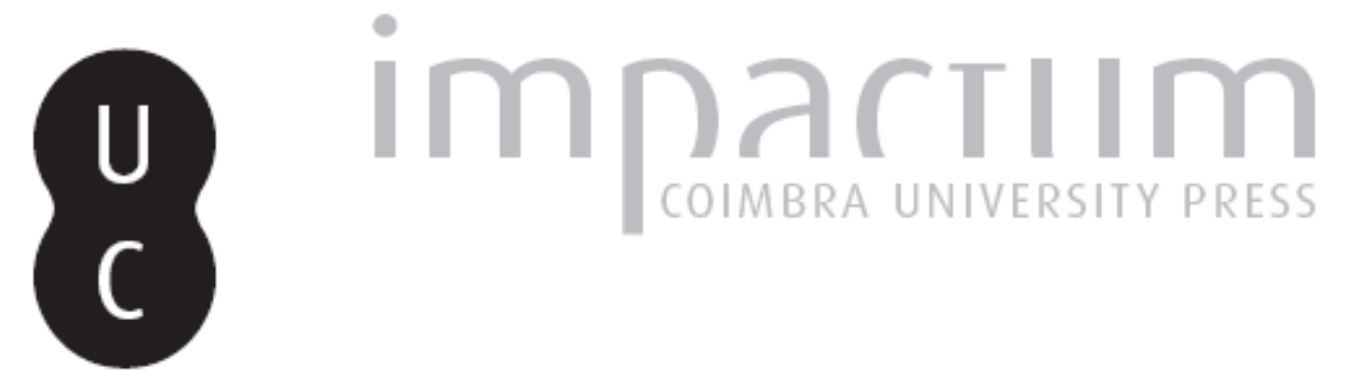

\title{
Viaggiatori portoghesi in Italia nella prima metà del Novecento
}

\author{
Autor(es): Mea, Giuseppe
}

Publicado por: Imprensa da Universidade de Coimbra

URL persistente:

URI:http://hdl.handle.net/10316.2/42389

DOI:

DOI:https://doi.org/10.14195/0870-8584_10_3

Accessed : $\quad$ 26-Apr-2023 15:28:50

A navegação consulta e descarregamento dos títulos inseridos nas Bibliotecas Digitais UC Digitalis, UC Pombalina e UC Impactum, pressupõem a aceitação plena e sem reservas dos Termos e Condições de Uso destas Bibliotecas Digitais, disponíveis em https://digitalis.uc.pt/pt-pt/termos.

Conforme exposto nos referidos Termos e Condições de Uso, o descarregamento de títulos de acesso restrito requer uma licença válida de autorização devendo o utilizador aceder ao(s) documento(s) a partir de um endereço de IP da instituição detentora da supramencionada licença.

Ao utilizador é apenas permitido o descarregamento para uso pessoal, pelo que o emprego do(s) título(s) descarregado(s) para outro fim, designadamente comercial, carece de autorização do respetivo autor ou editor da obra.

Na medida em que todas as obras da UC Digitalis se encontram protegidas pelo Código do Direito de Autor e Direitos Conexos e demais legislação aplicável, toda a cópia, parcial ou total, deste documento, nos casos em que é legalmente admitida, deverá conter ou fazer-se acompanhar por este aviso. 


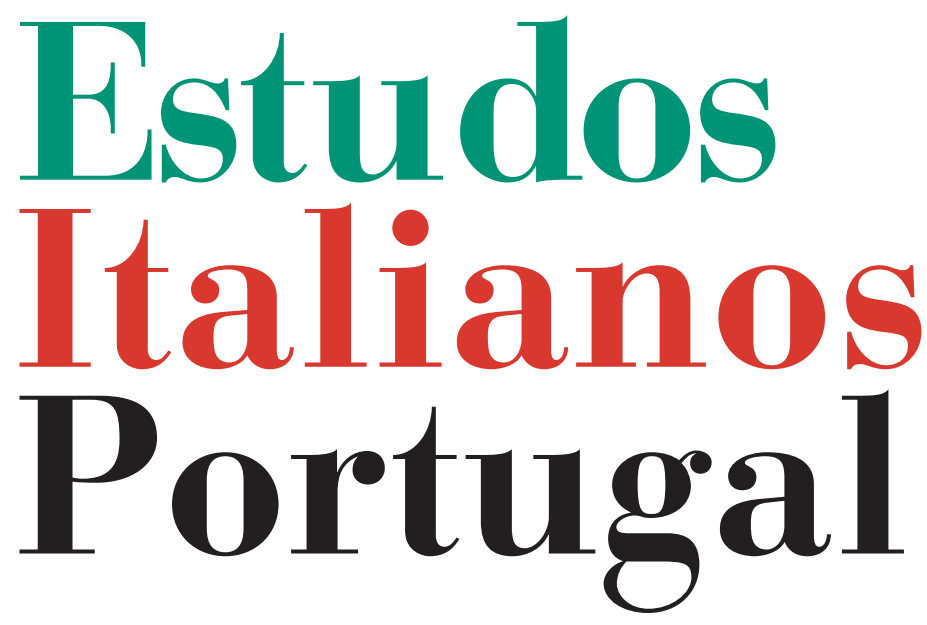

Instituto

Italiano

de Cultura

de Lisboa

Nova Série

$\mathrm{N}^{\mathbf{0}} 10$

2015 


\title{
VIAGGIATORI PORTOGHESI IN ITALIA \\ NELLA PRIMA METÀ DEL NOVECENTO
}

\author{
Giuseppe MeA*
}

\section{Il VIAGGIO E LA LETTERATURA DI VIAGGIO**}

LA LETTERATURA di viaggio, basata sull'esperienza diretta, si può dire che inizia con i già citati Essais di Bacon del 1597 e Of Travel del 1612 e raggiunge il suo auge nel Settecento e nell'Ottocento, quando decine e decine di letterati, poeti, pittori europei lasciano le loro testimonianze ed impressioni sul "Paese dove fioriscono i limoni", secondo una felicissima definizione di Goethe.

Il Portogallo sembra essere rimasto estraneo allo spirito del viaggio in Europa, se escludiamo Francisco de Holanda, l'unico grande nome portoghese di questi secoli, che va a

* Lettore di italiano presso la Facoltà di Lettere di Porto dal 1972 al 2008. Addetto all'Istituto Italiano di Cultura di Porto dal 1977 al 1993. Ha insegnato anche presso l'Università di Braga e l'Università Cattolica di Porto. È autore dei dizionari Italiano-Portoghese/Portoghese-Italiano editi da Porto Editora e Zanichelli. Ha pubblicato sempre per Porto Editora Gramática Prática da Língua Italiana.

** I libri analizzati e più volte citati nel presente articolo sono i seguenti: Justino de Montalvão, Italia coroada de rosas, Rio de Janeiro/Paris, 1910; A terra encantada, Rio de Janeiro/Paris, 1911; Jaime Cortesão, Itália azul, Lisboa, 1922; Ricardo Jorge, Passadas de erradio, Lisboa, 1924; Augusto de Castro, As mulheres e as cidades, Lisboa, 1926; Carlos Santos, Como eu vi a Itália, Lisboa, 1929; Abel Salazar, Uma primavera em Itália, Lisboa, 1934; Alberto d'Oliveira, Poemas de Itália e outros poemas, Lisboa, 1939; Luís Varela Aldemira, Itinerário estético. A caminho de Roma, Lisboa, 1943 (ope- 
studiare a Roma ${ }^{1}$. Le ragioni di questa estraneità può essere dovuta al fatto che in quei secoli l'attenzione del Portogallo era rivolta più a ovest e a sud che all'est europeo.

Inoltre l'Italia era molto distante dal Portogallo. Bisogna notare che allora un viaggio era davvero un'avventura; si viaggiava in carrozza o in diligenza o addirittura a dorso di mulo o di cavallo attraverso strade impervie, sconnesse, disagevoli, polverose d'estate e fangose d'inverno; a volte erano veri tratturi, senza posti di ristoro o locande minimamente accoglienti, sottoponendo il corpo a estenuanti fatiche, a malattie, a dolorosi fastidi e inconvenienti. E dopo, c'era il grande ostacolo delle Alpi. Per fare qualche esempio, la via ligure sarebbe stata resa interamente accessibile alla carrozza solo nel 1830; prima si arrivava a Marsiglia o a Nizza e si ci imbarcava per Genova, Livorno o Civitavecchia a seconda della destinazione. Andare da Firenze a Roma richiedeva dai tre ai cinque, sei giorni, mentre da Roma a Napoli dai due ai tre o quattro giorni. Carlo Alberto per coprire i 1.500 chilometri circa che separano Novara da Porto ci impiegò a tappe forzate ben 27 giorni (24 marzo - 19 aprile 1849), fiaccando il suo già debilitato corpo. L'avvento della strada ferrata rivoluziona il mondo dei trasporti. Con il completamento dell'ultimo tratto alpino nel 1880, l'Italia è facilmente raggiungibile dal Portogallo in pochi giorni.

Lopinione generale è che i treni italiani, usati anche per gli spostamenti interni, sono migliori dei portoghesi. Artur Portela dice addirittura che "Embarcamos numa confortável

ra scritta nel 1933); Cónego António José Ribeiro, Caminhos de Roma. Novos rumos, Braga, 1948; Artur Portela, Rosas de Itália, Lisboa, s.d. [1950-1951?]; Carlos D’Ornellas, Viajando pela Europa. I. Itália, Lisboa, 1951; Vasco César de Carvalho, Viagem a Roma, Vila Nova de Famalicão, 1953 (viaggio effettuato nel 1950 in occasione dell'Anno Santo).

${ }^{1}$ Il viaggio in Italia di Francisco de Holanda iniziò nel 1537-1538, essendo rientrato in Portogallo molto verosimilmente nel 1547. Di questo suo soggiorno romano, Francisco de Holanda ci ha lasciato Diálogos em Roma. 
terceira classe, com corredor, estofos, ar condicionado, equivalente a um salão de primeira classe nos nossos 'rápidos' de luxo. Não quero acreditar", ed ha il timore che abbia sbagliato carrozza (p. 128).

Differente è il viaggio di Justino de Montalvão (1910). Provenendo dalla Svizzera, entra in Italia dal traforo del Sempione, aperto nel 1906: "Estes titanicos Alpes [...] cuja travessia ainda ha poucos annos se fazia dramaticamente em diligencias prehistoricas, atravez de todas as ameaças d'avalanches tragicas, com paragens nos conventos onde viviam velhos eremitas isolados do mundo, faz-se hoje jovialmente em vinte minutos ligeiros." (p. 33).

Non è neanche contento del cronico ritardo con cui viaggiano i treni, che egli attribuisce all'indolenza dei popoli meridionali. Ma l'Italia non è soltanto "coroada de rosas"; ha anche le sue spine, e delle grosse. Quel periodo rappresenta il picco dell'emigrazione italiana all'estero e Justino de Montalvão ha l'occasione di farne esperienza personale nella stazione di Verona:

E, bruscamente, sofro a transicção violenta de me encontrar no meio de uma leva d'emigrantes esfarrapados. Estendidos no chão, embrulhados em cobrejōes, entre fardos e saccos, atulham a gare, as salas d'espera e os corredores, à espera do comboio da madrugada que os levará ao porto de Genova.

$\mathrm{Na}$ bruma fumosa, cruamente batidos pela luz das lanternas, prostrados de fadiga, lembram um exercito de vencidos. Nos seus olhos resignados de campónios ha a passiva taciturnidade dos que partem para um destino ignorado, Alguns são adolescentes ainda, saudosos das namoradas que deixaram, chorando, nas ilhas mortas do Veneto. Outros, velhos [...]. A um canto uma rapariga de cabellos fulvos [...]. E aquelles aldeãos, famintos e desgraçados como os que cada semana enchem os porôes dos paquetes em Leixões, dão-me a primeira impressão inesperada d'uma outra Italia tragica, contrastando com as ideias poeticas de prazer e vida facil que estamos habituados a ligar ao nome d'esta terra que é no emtanto aquella onde a maior abundancia 
alterna com a maior miseria e onde a emigração augmenta d'anno para anno n'uma progressão panica. (pp. 219-220)

Nell'immediato secondo dopoguerra, si incomincia già ad utilizzare l'aereo (4 ore di viaggio la tratta Lisbona-Roma) e per gli spostamenti interni gli autopullman: "Todas as grandes cidades italianas estão ligadas e bem servidas de rápidas carreiras de explêndidas caminhetas (auto-pulman) cuja velocidade, comodidade e asseio nada deixam a desejar nem podem ser facilmente excedidas" (Cónego A. J. Ribeiro, p. 31 ), che attraversano la nascente rete autostradale italiana:

A estrada sempre plana e sempre recta não é utilizada senão por viação automóvel e em toda a sua extensão não vi um único peão ou animal atravessá-la. De onde a onde, uma ponte ou um túnel dá vasão ao trânsito de peões ou veículos, sem que os automobilistas sejam perturbados naquela sua pista maravilhosa e ideal para as grandes velocidades.(pp. 162-163)

Ma anche in questo caso c'è qualcuno che ha qualcosa da ridire. Vasco César de Carvalho fa notare che bisogna pagare a "um funcionário de boné e bata branca" (pp. 103, 124) un pedaggio, mentre Carlos Santos fa dell'ironia, dicendo che sono strade per lanciare "poeira aos olhos do estrangeiro" (p. 101), perché le strade italiane sono pessime e "parecedíssimas com as de Portugal” (p. 101). Nell'ultimo quarto del XIX secolo, una volta completato il collegamento ferroviario Portogallo-Italia, sono pubblicati vari libri di viaggio sull'Italia ${ }^{2}$; gli anni '20 e '30 del secolo scorso sono quelli in cui è pubblicata la maggior parte dei libri di viaggio sull'Italia e dopo l'interruzione bellica si vede di nuovo un rifiorire di pubblicazioni intorno al 1950, in occasione dell'Anno Santo.

${ }^{2}$ Fra gli altri, bisogna citare António Alves Mendes da Silva Ribeiro, Italia. Elucidario do viajante, Porto, 1878 , il più completo e il più consultato. 
I viaggiatori provenienti dalla Penisola Iberica entrano in Italia dalla frontiera di Ventimiglia, e diventa quasi obbligatorio il seguente itinerario: Firenze - Roma - Napoli - Roma - Venezia - Milano; si fa il giro dell'Italia nel senso antiorario. Firenze, e in alcuni casi Genova, si presenta come la prima città italiana con cui prendono contatto.

Genova la Superba è anche la prima città dove sostare e riposare dopo un faticoso viaggio. La maggior parte vi si ferma poco tempo e le impressioni sono per lo più positive. C’è qualcun altro che si ferma ancora qualche giorno e ne approfitta per visitare la Riviera Ligure che dà a Jaime Cortesão la possibilità di fare le seguenti considerazioni:

E é tal a atmosfera pagã desta riba marítima que o vestuário de banho, em homens e mulheres, suportado sobre a pele, talvez por um resto de culto às impertinências modernas, oscila, para glória dos Deuses, entre um nadinha mais e um nadinha menos que a folha de vinha. Vive-se assim na praia; e assim vestido se anda por terra ou pelo mar, nos pequenos barcos de recreio. Estirados na areia, amparados uns aos outros, ou emergindo da espuma, vêm-se corpos de estátua levissimamente envoltos e embevecidos na música das poses, com graça indolente e adonísica. Qualquer observador por pouco atento pode fitar os corpos quase nus até às curvas íntimas. Uma facilidade extrema nas relaçôes aproxima os dois sexos. Após uma apresentação, feita dum e doutro lado pelos próprios interessados, aí começa um destes mil pequeninos romances da praia lestos e suaves, aos quais a moleza tépida do Mar amacia os últimos atritos, discreta alcovitice com que Neptuno auxilia Vénus no inefável epílogo da história.(pp. 51-52)

Carlos Santos, invece, la Riviera ligure ce la presenta così: “a Riviera do Poente é a costa dos Estoris e Cascais, protegida pela Serra de Sintra; a Riviera do Levante é a faxa atlântica desde Outão até Cezimbra, na qual a Arrábida exerce as funções de serra protectora de enseadas, como na Itália os Alpes" (p. 169), e che Sanremo è la Estoril italiana (p. 175). 
La prima grande sosta è indubbiamente Firenze, e qualcuno coglie l'occasione di visitare Pisa, città soave e silenziosa (J. Cortesão), triste (L. V. Ademira), vedova (J. de Montalvão), patria di Galileo e Pacinotti, mentre Siena è completamente ignorata. Fra coloro che visitano Napoli, alcuni si recano anche a Pompei. E Napoli è il confine estremo del viaggio; a sud è terra sconosciuta, agreste.

Andando verso Nord, Bologna è saltata a piè pari da tutti e una volta a Venezia, qualcuno si ricorda di andare a Padova non tanto per motivi religiosi ma più per motivi campanilistici, reclamando la paternità portoghese del Santo che i patavini hanno usurpato e contestando l'uso improprio della proposizione da (Sant'Antonio da Padova).

Da Milano qualcuno ne approfitta per visitare la zona dei laghi. Parlando del lago Maggiore Justino de Montalvão dice: "N'uma manhã de maio de 1864 , ao voltar da sua viagem atravez de toda esta Italia que tanto seduziu sempre as imaginações estheticas, Taine escreveu: 'Se eu tivesse de escolher uma casa de campo, seria aqui.' Tal foi também a minha impressão.” (p. 48), mentre Abel Salazar e Jaime Cortesão restano affascinati dal Lago di Como.

Anche Torino non suscita molto la curiosità dei viaggiatori portoghesi. Per Abel Salazar è una città ampia e simpatica, quasi germanica, urbana e civile ma senza nessun interesse; l'idea generale è che non ha la monumentalità di Roma, né la bellezza magica e seduttrice di Venezia, né la bellezza storica di Firenze o il cosmopolitismo di Milano. C'è anche chi invita a visitare la Basilica di Superga, dove sono sepolti Carlo Alberto, morto a Porto nel 1849 e la sua sventurata nipote Maria Pia di Savoia, la penultima regina del Portogallo. Per quanto riguarda la Sardegna, silenzio assoluto su quest' isola considerata ancora remota e primitiva e che sarebbe stata scoperta come luogo di villeggiatura dalla jet society internazionale solo negli anni ' 60 . 
La maggior parte dei viaggiatori portoghesi si fa accompagnare da un Baedeker, dove, oltre ad attingere notizie sulla località da visitare, può trovarvi anche dei consigli pratici. Ma prima del viaggio, o durante, ricorrono anche a libri di viaggi più o meno recenti. Il più letto e seguito continua ad essere il Voyage en Italie di Hippolyte Taine, del 1864, o una delle varie opere sull'Italia pubblicate da Jonh Ruskin (1819-1900). Molto seguito è anche En el país del arte (Tres meses en Italia) di Blasco Ibañez (1896), mentre come autori portoghesi il già citato António Alves Mendes da Silva Ribeiro, e i due volumi, rispettivamente del 1910 e 1911, di Justino de Montalvão.

\section{L'ITALIA E GLI ITALIANI}

[A Itália] essa terra de sol, de azul, de rosas e de arte. Aquilino Ribeiro, Carta-prefácio ao livro de Carlos D’Ornellas

Fino alla metà del XX secolo i viaggiatori si recavano in Italia per visitare soprattutto le città d'arte. L'Italia era considerata (e lo è tuttora) la culla e lo scrigno della civiltà occidentale, la terra della classicità, la depositaria di un immenso patrimonio artistico.

O país rico e exuberante de privilégios inconfundíveis por belezas sem par e a quem a cor dos séculos garantiu a condição de País da Arte.(V. C. de Carvalho, p. 166)

Uma doce e suave lembrança dessa grande nação tão rica de monumentos incomparáveis e de obras-primas da arte e de beleza.(A. J. Ribeiro, p. 179)

Justino de Montalvão, da parte sua, che definisce l'Italia "Terra encantada", parlando delle sue ricchezze artistiche scrive: "Poderia dizer-se que a Italia verdadeiramente viva para os artistas, é a Italia morta" (p. 247), e altrove: "É por 
isso que entre todos os paizes, se Portugal é a patria do meu coração, a Italia é a patria do meu instincto. Como compreendo os pintores, os artistas, os poetas que aqui vieram por dois mezes, e nunca mais a poderam deixar." (p. 52).

Ma l'Italia è anche il paese del sole, il luogo dell'oblio, il paese più sentimentale del mondo, come fa dire dalla bocca di una signora Augusto de Castro (p. 137). Ma i viaggiatori non tralasciano di ammirare i paesaggi affascinanti che attraversano. È sempre Justino de Montalvão che ci dice: "Sob a clara e macia doçura do clima mediterraneo, não só o homem é mais expontaneamente artista: a propria natureza revela uma elegancia mais esculpturalmente harmoniosa." (p. 42) Le bellezze paesistiche toscane incantano Jaime Cortesão (A sagrada terra da Toscana, p. 159) e Justino de Montalvão:

À graça ambiente da natureza devem os toscanos a superioridade do gosto, o sentimento attico da belleza, a finura da imaginação creadora, o culto das nobres formas e das linhas harmoniosas.(p. 61)

Mais graciosa do que exuberante, a natureza revela aqui o mesmo caracter de harmonia e proporção que a arte toscana. Ao passo que a paisagem veneziana, toda em espalhamentos irisados d'aguas, vaporosidades fluidas de nuvens e reflexos cambiantes de tintas continuamente fundidas, inspirou a pintura voluptuosa dos maiores coloristas, a Toscana, com suas esculpturaes collinas d'um relevo de curvas nitidas e seus horizontes de contornos solidos, produziu os maiores architectos e estatuarios da Italia.

Com valles viçosos e vertentes suaves de outeiros arborizados de amoreiras e oliveiras, sulcada de filas parallelas de vinhas, esta paisagem, mais fresca e unida que no resto da península, lembra um pouco, pela patriarcal abundancia, a do Minho idylico. Mas ha n'esta alguma coisa de mais fino, de mais estylisado, com os pinheiros abertos em paleo, e os cyprestes esbeltos que se perfilam, em tão hieratica delicadeza, nos terraços das villas elegantes e nas ruinas dos castellos cheios d'heras e de lendas.(pp. 63-64) 
Ed è anche il Minho che ricorda il Cónego A. J. Ribeiro quando attraversa la campagna campana diretto a Napoli:

À medida que nos avizinhamos de Nápoles, mais nos encanta o aspecto da feracíssima e verdejante região que a rodeia. A terra toda cultivada em tratos geométricos, de milho, trigo, cânhamo, batata, os renques de grandes choupos a suster abundante vidonho de enforcado, tudo nos dava a ilusão de atravessar certas regiões do nosso Minho.(p. 106)

Per Artur Portela, invece, è il paesaggio umbro quello che lo affascina di più:

Ao longe, no último plano, os montes lilases e de suaves linhas da Úmbria, e depois num largo círculo de quilómetros, a toda a volta do horizonte, uma extensa e calma planície, cortada de tiras de loiro trigo, que parece maturar aqui mais cedo, e de estreitas passadeiras de uma vegetação virente e engrinaldada de vinhas, tão macia, tão lisa que parece pintada em vidro. A paisagem idílica, de uma serenidade extasiante, sobre a qual a concha azul do céu despeja uma luz clara e suave, está cheia de árvores, todas tamaninas, como se não quisessem crescer muito $[\ldots]$.

São oliveirinhas cinzentas, prateadas, mais brancas do que as nossas, ciprestes esguios, em ogiva, marcando caminhos preguiçosos, pinheiros de coma rala, como que ressequida, de tal modo esparsos, divididos, caprichosos que a visão desta altura, a mais de mil e duzentos metros, não encontra uma espessura hostil, nem uma vereda cerrada. (pp. 281-282)

Se dovessimo scegliere un sostantivo e un aggettivo che ricorrono più frequentemente nei nostri autori, il sostantivo sarebbe indubbiamente "bellezza" ("A Itália - o país eleito da beleza", dice Jaime Cortesão) mentre l'aggettivo sarebbe "azzurro". Questo termine è un vero leit-motiv per Jaime Cortesão: oltre ad intitolare il suo libro Itália azul, ci dice ancora: "Mas, apenas entrei nessa delícia azul do mar mediterrâneo, tão brando, tão afável, tão voluptuoso, e por tanta 
e diversa maneira diferente deste bárbaro Atlântico, depressa adivinhei, dentro da alma inebriada, os motivos que levaram os homens a disputar aquelas margens, com tão desesperado afinco" (p. 13), e più oltre: "Eu não vi jamais na Itália e em vida minha tão celeste azul do Céu!" (p. 171).

Immagine dataci anche da Ricardo Jorge: "azuleja o cariz do céu sobre o zimbório de Santa Maria del Fiore” (3. a ed., s. d., p. 3), mentre Justino de Montalvão parla di "mares azuis" e Vasco César de Carvalho della "visão azul deste mar" [il Tirreno]. Potremmo continuare ma è preferibile fermarci qui per non allungare troppo l'elenco.

Ma visitare l'Italia e vedere da vicino le sue immense ricchezze artistiche e paesistiche ha un costo: le lire, tante lire, moltissime lire. Sono cari i ristoranti, una passeggiata in gondola costa un occhio della testa, prendere un taxi è un lusso, ecc.

Abel Salazar, trovandosi a Venezia, arriva ad un certo punto che non resiste e sbotta:

E são liras ver um quadro célebre, uma igreja, uma sacristia famosa; liras ainda, pagas num guichet, para ver o tesouro de S. Marcos; liras sempre, em qualquer parte, para ver qualquer, a tal ponto que se receia, ao contemplar uma fachada caduca, ou um velho palácio, que alguém surja, reverente mas implacável, exigindo o tributo, ainda e sempre uma obsessão...(p. 139)

E questa "tendenza" continuerà anche nei decenni seguenti. Augustina Bessa-Luís, nel 1959, si lamenta dei prezzi esorbitanti delle autostrade o dei generi alimentari ed anche del rapporto prezzo/qualità. Trovandosi a Siena scrive:

Rimo-nos da pobre fatia de vitela que pagamos como se fosse uma fêvera de javali ou uma talhada de bossa de bisonte. Rimo-nos daquela grande feira em que circulam criados com os colarinhos moles de suor, e onde cheira a sopas refervidas e donde nos apetece partir sem pagar, por simples devaneio, por réplica conscienciosa. A obsessão de furtar alguma coisa, de subtrair uma colher, de pegar num cinzeiro, de levar 
um objecto qualquer do balcão duma loja, começa a perseguir-nos. Não se pode viajar em Itália muito tempo sem sofrer o contágio daque-le desplante ao apresentar uma conta e ao fixar um preço. Rimo-nos ao beber a gota de café que nos trazem no fundo da chávena ${ }^{3}$.

Se questa è l'Italia che è stata dipinta con tutti i suoi chiaroscuri (i chiari di gran lunga superiori agli scuri), per quanto riguarda gli italiani, a parte lo sconcerto che prova Jaime Cortesão quando vede che in Italia gli uomini si baciano fra di loro sulle guance, aggiungendo "em Roma sê romano" (p. 46), si nota la totale assenza di stereotipi che li hanno accompagnati e continuano ad accompagnarli ${ }^{4}$. Molto interessante invece è l'analisi che Justino de Montalvão fa del rapporto degli italiani con la religione:

Porque embora se chrisme de catholico, todo este povo, no intimo, ficou sendo pantheista. No christianismo, o que encantou sempre não foi a espiritualidade da douctrina, mas a pompa das ceremonias lithurgicas, das procissōes, das imagens, das festas brilhantes e sumptuosas.(p. 43)

A religião na Italia é um sentimento espiritual de ternura amorosa e serena, inteiramente diverso do fanatismo hespanhol, tragico e violento. Nas madonas dos altares transparece a mulher, a amante que serviu de modelo aos mestres que a idealisaram, depois de a terem beijado e cingido nos extases carnaes. A Virgem d'Urbino tem os traços da Fornanina. Nenhuma das santas italianas mostra os livores asceticos, a pallidez macerada de Theresa de Jesus.(p. 46)

O povo italiano parece, de resto, reconhecer que as suas egrejas são antes muzeus, onde se passa, que logares de devoção, onde se estacione.(p. 222) Com os pequenos lenços de assoar, que costumam pôr em triângulo,na cabeça, ao entrar no recinto sagrado, as mulheres pedem á Madona que lhes conceda o premio no «loto", se são já velhas, ou um bello «fidanzato», se são novas.(p. 223)

${ }^{3}$ Augustina Bessa-Luís, Embaixada a Calígula, Lisboa, 1960, pp. 261-262.

${ }^{4}$ Fatta eccezione di Carlos Santos, che più di una volta, parlando degli italiani, rasenta l'offesa. 
Quanto mais convivo com este povo e lhe vou auscultando a alma prodigiosa, atravez das manifestações artisticas, dos costumes, das lendas, e da historia, a noção que se me precisa no espirito é a de que elle nunca foi sinceramente christão.

A tendencia natural para a realidade, o gosto inato do prazer, das artes plasticas, da poesia e da musica amorosas, da religião da vida, em todas as suas modalidades naturaes, predominaram sempre n'elle sobre as divagações espirituaes.(p. 224)

O mysticismo nunca foi portanto, n'esta dôce terra amorosa, senão um accidente anormal, uma crise morbida, transitoria como as epidemias que assolavam as multidōes apavoradas.(p. 227)

Più numerosi, invece, sono i riferimenti alle donne italiane, siano esse torinesi (carnudas e brancas: A. Salazar, p. 35), romane (os seus corpos ritmicos, ondulantes, bem marcados de forma; olhos castanhos ou escuros, mas grandes; mais flagrantes do que flores e mais belas do que frutos: A. Portela, pp. 26; 79; 284), fiorentine, dalla (nervosa e espiritual formosura: J. de Montalvão, p. 96) o milanesi (formosissimas mulheres, com seu sorriso quente, como uma rosa aberta sobre os lábios e aqueles olhos voluptuosos: J. Cortesão, p. 237).

\section{LE CITTÀ}

São como as cidades as mulheres Justino de Montalvão

Le osservazioni, le note, $\mathrm{i}$ giudizi dei viaggiatori sulle città italiane variano a seconda della loro cultura e dei loro interessi, L'occhio dello storico è differente da quello del giornalista o del pittore. Quindi Roma e il fascino dell'antico costituiscono il richiamo principale dei cultori della classicità, mentre Firenze esercita un grande ascendente sugli amanti dell'arte.

Firenze, al pari di Roma, di Napoli e di Venezia, e un po' meno di Milano, non conosce declino nella lunga stagione del viaggio in Italia e per tutti i viaggiatori sono tappe indi- 
spensabili. Per tale ragione, seguiremo l'itinerario già tracciato anteriormente per descrivere queste cinque città, premettendo fin da ora che ogni città ha una sua propria fisionomia differente dalle altre, un carattere particolare, inconfondibile.

Firenze

Cidade florida de nome e de emblema Ricardo Jorge

Fermata obbligatoria per qualsiasi straniero che si rechi in Italia, Firenze era, come è già stato detto, la prima tappa di tutti coloro che provenivano dalla Penisola Iberica in treno.

Capitale della Toscana, terra felicissima nata e creata nel culto della bellezza, ha visto nascere o vivere Dante (il suo cantore), Giotto, Botticelli, Leonardo da Vinci, Michelangelo e tanti altri che hanno segnato la cultura italiana come Petrarca, Boccaccio, Machiavelli, Galilei, come ci ricorda Jaime Cortesão (pp. 159-165). Firenze è, a detta di tutti, un museo vivente, un museo a cielo aperto, la città dei Medici, patrimonio dell'umanità.

Questa città immortale che ha affascinato intere generazioni di viaggiatori è rimasta impressa in molti viaggiatori portoghesi per la sua "volúpia".

"Voluptuosa"; "Florença como uma extenuada amante, descobre e oferece a inebriante sensualidade da sua nudez de mármore"; "Florença é a mais linda mulher florentina" (A. de Castro, passim); "Cidade de arte, de amor e de volúpia" (A. Portela, p. 178); "Florença-a-amorosa" (J. de Montalvão, p. 71). Abel Salazar, invece, si limita ad un laconico "Florença é a mais bela cidade da Itália” (p. 61), aggiungendo:

Há cidades onde se não pode "flanar"; noutras, como em Florença, gira-se ao acaso pelo prazer de andar, embalado na réverie letárgica das velhas pedras, das velhas ruas, entre altaneiras frontarias negras e 
severas, ou ladeando joalherias de pedra esculpida por dedos feiticeiros. Mas para isso é necessário jamais consultar o Baedeker, ter o bom gôsto de ignorar os nomes de paços e palácios, de domos e de agulhas, de ignorar emfim tôda a história, tudo sepultando nêsse vago tempo indeciso em que a fantasia paira sem entraves de fórmulas definidas. (p. 81)

Roma ${ }^{5}$

Tudo fumega a antiguidade Francisco de Holanda, Diálogos em Roma

Abel Salazar dice che a Roma si fondono o si sovrappongono tre città differenti, la Roma moderna, la Roma dei Cesari e la Roma dei Papi (p. 87). Di tutti questi strati, il visitatore è attratto di più da quello latino, classico, cesareo, perché, al contrario di città come Troia, Ninive, Babilonia, Cartagine, divenute leggendarie in quanto non vi è rimasto nulla, Roma è concreta, palpabile, tangibile. E Jaime Cortesão, da storico, rivede nelle rovine di Roma i grandi fasti del passato, Giulio Cesare, Antonio, Augusto, Tito e si sente commosso, emozionato (soffrendo un po' la famosa sindrome di Stendhal), una città che non si finisce mai di percorrere e meditare ( $\mathrm{p}$. 127), aggiungendo che da portoghese è orgoglioso di essere discendente dai latini (p. 71).

Ma la Roma dei Cesari è soprattutto il Colosseo, imponente, virile, simbolo della sua potenza mondiale. Ricorriamo di nuovo a Jaime Cortesão, che gli dedica un capitolo intero nel suo libro:

De súbito a sugestão do cenário e da memória lança-nos em aura visionante. A tragédia revive aos nossos olhos. Do ático ao pódio, a multidão, mais de cem mil espectadores, num tremular de túnicas e

${ }^{5}$ Su questa città si veda Valerio Magrelli, Magica e velenosa. Roma nel racconto degli scrittori stranieri, Bari/Roma, 2010. 
togas, estremece e murmura com antegozo e ansiedade. A um sinal do Imperador, o espectáculo abriu. Já a primeira vítima humana foi degolada em sacrifício a Júpiter. Pela arena desfila o cortejo faustoso e reluzente dos que vão morrer. Agora, em frente da tribuna imperial ergue-se, em coro, voluptuoso e sublime, o canto de abertura: Ave César, morituri te salutant. Os combates começam. A multidão, de olhos em brasa, arfa como o velário rubro, suspenso ao alto. Um silêncio mortal. Eis um dos contendores caiu por terra. E então (imaginoso delirar!) erguemo-nos de súbito ou debruçamo-nos de repelão sobre a arena, sacudindo a toga ou o laticlavo de púrpura, e estendendo o braço nu, de polegar abaixado, bramamos pela morte do gladiador vencido, afogando a vista com delícia na maré rubra de sangue, que lhe extravasa das artérias.

Depois abrem-se os cárceres: entra na arena a turba das feras rugidoras. Escravos e animais tombaram por milhares. Correram rios de sangue pelo chão. E, a multidão, cuja embriaguez nos empolga também, possessa do delírio vermelho, torce-se, ulula, geme, num espasmo de lubricidade sanguinária ${ }^{6}$.

Il simbolo della Roma dei Papi è più controverso: la Basilica di San Pietro. Gli apprezzamenti di tutti i viaggiatori non sono benevoli. Si va dal "poderoso, mas enfático" di Luís Varela Aldemira, citando Taine (p. 284), al "rico, grande, arrogante, mas não belo" di Carlos Santos (p. 335), al "luxurioso, pesado, maciço, sem nobreza” di Abel Salazar, il quale aggiunge:

Penetrando no interior, recebe-se uma impressão, que uma frase cruel pode definir: a duma estupidez bárbara, pretenciosa e mole. Sem grandeza nem elevação, o conjunto das grandes naves é vasio de espírito religioso, verdadeiro; é uma cenografia teatral de fórmulas arquitectónicas dispostas com o fim de impressionar espíritos incultos e ingénuos, pela justaposição pesada de elementos espectaculosos, mas

${ }^{6} \mathrm{Pp} .84-85$. Per una ricostruzione più approfondita si veda António Alves Mendes da Silva Ribeiro, pp. 99-105. 
sem ritmo ou unidade. O efeito resultante é ao mesmo tempo religiôso e mundano, ou, melhor, nem é religioso nem mundano, pois é ambíguo; emfim, um vasto cenário de pedra destinado a abrigar uma mise-en-scène teatral e espectaculosa. É ao mesmo tempo um trono, um salão e um teatro; não comove, nem perturba nem faz pensar, produzindo apenas uma impressão de frio pasmo. [...] A catedral gótica purifica, a catedral romana bestifica; uma depura, espiritualiza e eleva; a outra sensualiza, materializa e abaixa; uma vai direita à alma, a outra procura a sua via pelos sentidos; uma recolhe-se ao receber o crente, a outra coquetiza-se; uma concentra-se e ensina-o a orar; a outra prostitue-se.(pp. 110-112)

Ancora più severo è Jaime Cortesão che qualifica la Basílica "pesada, desgraciada, desconforme, abortiva, desmesurada, monstruosa", lanciandosi dopo in un furioso attacco contro la Chiesa di Roma (pp. 129-130).

Totalmente differente è la visione che Augusto de Castro ha sulla Basilica di San Pietro, che egli chiama "Basílica de Fogo", dedicandole un capitolo del suo libro. In una domenica di maggio del 1925, egli si trova a Piazza San Pietro per assistere alla cerimonia di canonizzazione di Santa Teresa di Lisieux. Da credente, ne descrive la cerimonia apoteoticamente, abbandonandosi ad una breve storia della Chiesa e del Papato, e riferendosi propriamente alla Basilica, scrive: "A Basílica vive, ígnea, sobre Roma deitada em sombra a seus pés, ergue no espaço, em torrentes de oiro, o seu faustoso sonho de eternidade - e essa deslumbrante chama, feita de mil chamas, canta, sobre o grosseiro materialismo da vida, a glorificação esplêndida do Espírito.” (p. 155)

La via di mezzo di queste due visioni così contrastanti ci è data da due ecclesiastici. Il "Cónego" António José Ribeiro scrive: "Não se vá à Basílica de S. Pedro buscar a humildade da Fé, nem a pobreza dos primeiros séculos, nem o cristianismo simples da idade média. S. Pedro é um triunfo, não uma aspiração, uma apoteose, não uma prece, uma presença, não uma invocação." (p. 44) 


\section{Napoli}

Nel 1833, quattro anni prima della sua morte, Leopardi andava a vivere a Napoli, dove si credeva che l'aria fosse salubre, per cercare di lenire i suoi patimenti fisici. Ma i visitatori che si inoltravano fino all'estremo sud del loro itinerario, non ci andavano per "cambiare aria", ma per ammirare, essendo una città meno interessante dal punto di vista artistico di Firenze o Roma, le bellezze naturali e le splendide vedute ${ }^{7}$, che incantarono Stendhal, Goethe, Flaubert, Lamartine, Taine, Byron, Blasco Ibañez, Alves Mendes e tantissimi altri. Il golfo che è una grandiosa vista di mare, Capri, l'isola più bella del mondo, secondo Vasco César de Carvalho, e che gli fa ricordare per molti aspetti Madeira, con la sua grotta azzurra, "um dos panoramas mais vastos, variados e empolgantes que a olhos humanos é dado ver" (A. J. Ribeiro, pp. 108-109), "a féerie que se oferece a nossos olhos não tem rival no Mundo" (A. de Castro, p. 19), «la costa che va da Posillipo a Sorrento, "panorama deslumbrante [...] mas pacífico e azulino" (A. J. Ribeiro, p. 109), "costas celebradas por Virgílio» (A. de Castro, p. 16), il Vesuvio che sovrasta la città.

E Napoli? "Orgia de luz e alegria"; "Roma severa e Nápoles hilariante", "cantos, músicas, risos enchem o ar" (J. Cortesão). "Colorida, gritante, levantina e exuberante", "pitoresca, alegre e pobre" (A. Portela), una città, a detta di tutti, dove vigono la confusione e il chiasso nei rioni antichi e popolari e il napoletano espande una gioia rumorosa, dove si sentono grida, discussioni dappertutto, sotto i panni stesi al sole su corde che vanno da una parte all'altra della via. Insomma una città tipica, pittoresca, da conoscere nelle vie, allegra, esuberante, teatrale. La miglior descrizione della vita di Napoli ci è data da Jaime Cortesão, che ci descrive la città con i suoi

"A esplendidez magnífica da natureza explica também que Nápoles não possua grandes monumentos”, J. Cortesão, p. 98 
scugnizzi (bambini, in dialetto napoletano), i posteggiatori con le loro pianole, i mendicanti, gli acquaioli, i venditori di angurie e di fichi d'india, di ostriche e di souvenir. La Napoli anche con i suoi bassi - "favelas sem sol" - come li definisce Artur Portela, e i lazzaroni, terminando con questa bellissima frase: "E Nápoles, bacante nua, fatigada da orgia, estira-se, morena e imóvel, na sombra tépida, sobre o seu fundo manto de veludo azul." (p. 101)

Ma non a tutti è piaciuta Napoli, come, per esempio, a Vasco César de Carvalho, anche se ammette che i napoletani sono sempre allegri e di buon umore, canticchiano sempre, anche quando hanno fame e non hanno lavoro. Jaime Cortesão fa notare che è una città sporca; ma la descrizione più severa sulla sporcizia della città è data da Abel Salazar, che si dichiara "desiludido".

Com a imundicie tapetando, em esteirado fôfo, as largas ruas, com as suas comadres despenteadas, ao sol, em toilettes íntimas e públicas, com o desmazêlo indiferente, ao mesmo tempo cínico e ingénuo, da sua vida meridional, Nápoles estende-se, batida de luz, no anfiteatro da sua baía. Um à-vontade caseiro por toda a parte; procuram-se parasitas por entre cabelos negros, que brilham ao sol, e farrapos íntimos, sujos, embandeiram as fachadas, gotejando sôbre a rua. Dir-se-ia que a população vive de rendimentos, gosa o sol, boceja e desconhece a palavra trabalho. As mulheres sorriem-nos, com olhos negros e os garotos perseguem-nos; no hotel, onde se torna difícil e complicado o problema da toilette, graças à imundície da bacia, a dama dirigente, mal penteada e reluzente de cêbo, declara-nos ser um legítimo rebento da mais alta nobreza italiana, emquanto um creado sórdido, com ares de salteador, se ocupa das malas, com mãos inquietantes. No refeitório, o viajante, emquanto limpa cuidadosamente o prato duvidoso, passeia os olhos um pouco estupefacto pelas paredes outrora brancas, cinzentas de imundície que escorre em longas, plangentes lágrimas, ou comtempla de soslaio a casaca ambígua do creado, dum negro em demasia brilhante. Em certas ruas o passo é amortecido por fôfa tapeçaria, de composição complicada muito antiga, e nos ares pairam 
perfumes aparentados com aquele que outrora uma freira famosa guardava num frasco cuidadosamente rolhado... Oh!, sim! vêr Nápoles e depois morrer, sem dúvida, é forçoso, uma determinação lendária. (pp. 115-116)

\section{Venezia}

Per Jaime Cortesão è una "cidade voluptuosa”, mentre Abel Salazar, Justino de Montalvão e Artur Portela si soffermano sulla descrizione e sull'analisi - soprattutto psicologica - di questa città. La prima cosa che Abel Salazar ci fa notare è che è una "cidade virgem dos ruídos dos trens e das buzinas de autos" (p. 143), "não tinem eléctricos, não gemem plangências de businas nem rolam fragores de carruagens" (p. 158).

E o silêncio de Veneza - que não é morte - esta grande calma em que se agita a cidade, esta paz morta em que tudo vive, sem guinchos de sirenes e roncos de buzinas, sem trepidação de movimentos, sem mesmo os passos se fazerem ouvir, - êste grande silêncio que perturba numa cidade povoada, é para mim a grande magia de Veneza.(pp. 193-194)

Ma cosa è realmente Venezia agli occhi di Abel Salazar?

Ela nos aparece, emfim, a revelar-nos a sua verdadeira alma, volúvel na sua opulência um pouco apressada, original na sua fusão desordenada de estilos, estranha na sua vida semi-terrestre, semi-aquática. Voluptuosa e mesquinha, sumptuosa e pelintra, cativante e odiosa, com a sua alma feita de contrastes, ao mesmo tempo orgulhosa e humilde e no fundo cínica, ela não se define jamais, por uma fórma conclusiva, mas hesita sempre, e desnorteia. Dir-se-ia até traiçoeira, por vezes, com as suas expressōes nimbadas de enigma, dúbias, de dupla face, fugidias, como capas de crimes, carícias de criança e atitudes teatrais, orgulhosas, altivas que desconcertam.(p. 144) 
E infine non può tralasciare di descrivere i turisti che affollano la città:

Num hotel moderno, dum luxo banal, qualquer, damas em extrêmo esguias, duma magreza aflitiva, conversam ruidosamente, fumam cigarros, num à vontade masculino, um pouco garôto; as eternas inglesas, sêcas como figos vélhos, e as pesadas prussianas, rubras como cenouras, agitam-se em todos os sentidos, grasnando na sua linguagem áspera. E à noite, no salão sumptuoso de S. Marcos, ao som embalador de orquestras, uma multidão em toilette passeia carregada de spleen, ou boceja indiferente nos cafés-cabines que ladeiam a praça.(p. 138)

Os altivos tiranos de Piccadilly, Broadway, de atijoladas carnações nas faces escanhoadas e esplendentes peitilhos de casacas, cruzam-se, indiferentes, com prussianas quadradas, polícromas como cacatuas, russas dum louro nevoento, esguias misses, sêcas e ossudas, de cigarro na bôca sangrenta de baton, cabeleiras de desconhecidos poetas e artistas.(p. 157)

Per Justino de Montalvão, Venezia è una città-nereide, una città-sirena, che denota soltanti antichi fasti:

A Veneza d'hoje è una cortezã decaída na velhice, curvada ao peso do enorme passado, cheia da fadiga d'uma longa vida de prazeres, de loucuras, de crimes e vicios magníficos, guardando apenas, com coquetteria macabra, sobre o corpo engelhado, todas as jóias da mocidade. [...] A sua decrepitude tem o melancholico prestigio das realezas destronadas, a nostalgica fascinação dos passados d'amor e d'aventura.(pp. 139-140)

E congedandosi dalla città scrive: "Tu foste para mim a cidade ideal, imprevista, maravilhosamente absurda, que não lembra outra. Nenhuma me deu emoçóes tão embriagantes como as que tu me deste, oh cidade voluptuosa e triste em que se não pode senão amar, sonhar, viver n'uma opera magnifica de dyonisiaco lyrismo." (p. 215)

Artur Portela, pur definendo Venezia la città più bella e voluttuosa del mondo e un pezzo del paradiso caduto dal cielo, 
e che vive euforicamente per strada, ribadisce quello che altri avevano già notato e descritto:

A primeira impressão que recebemos de Veneza é a de que ela é uma grande ruína. As fachadas esboroam-se sem que alguém lhes dê uma demão de cal. As janelas não se fecham, as paredes desagregam-se e os majestosos palácios brasonados sobre o Grande Canal - onde perpassam, ágeis e fugidias como cisnes negros, as gôndolas - estão desertos, fechados, tocados pelo mal irreparável da morte.(p. 213)

\section{Milano}

Passar em Milão sem ver o 'Cenacolo' seria o mesmo que ir a Roma sem ver, não o Papa, que é apenas um bom homem, mas a Capella Sixtina, que é uma maravilha divina Justino de Montalvão

Pur riconoscendo che è il centro commerciale, finanziario, industriale ed anche intellettuale d'Italia, che è una città moderna, ricca, lussuosa, sempre in movimento e piena di vita, Milano non desta molto l'attenzione dei visitatori, perché, oltre al Duomo e al Cenacolo, la città non offre molte altre cose da vedere.

Una città più nordica che italiana (A. Salazar), la meno italiana di tutte le città italiane (J. de Montalvão), una città amorfa, ma allo stesso tempo forte, violenta, varia, imprenditrice e sontuosa (J. Cortesão).

Però è una città che si fa amare, come afferma Justino de Montalvão:

Sem o encanto do mar que a emoldure de esplendores cambiantes, como Veneza, Genova, Napoles, ou as molles cidades da Sicilia, onde floresce uma immortal primavera; sem collinas harmoniosas, como Florença, a citá [sic] felicissima, nem nobres ruinas como Roma, Vero- 
na, Ravena, Piza ou Sienna; sem rios de bellas margens como o Arno e o Tibre; apenas com dois regatos tão humildes, o Seveso e o Olona, que ao chegarem ás portas da cidade se escondem, entre muros, como os pobres envergonhados, Milão sabe fazer-se amar por razôes d'ordem moral.(p. 71)

Ma agli occhi dello stesso scrittore non sfugge l'aria di arroganza con cui i milanesi guardano gli italiani del centro-sud.

Quando o milanez falla do romano ou do napolitano, de todos os povos do sul, em geral, onde a doçura do clima incita mais ao far-niente, ao lazzaronismo, é sempre com o encolher d'hombros, o sorrizo de indulgencia desdenhosa do homem que trabalha e se vê forçado a pagar as loucuras e a occiosidade d'um irmão estroina.(p. 70) 